\title{
Acquired Factor V Inhibitor after Coronavirus Disease 2019 (COVID-19)
}

\author{
Federico Chiurazzi, MD ${ }^{1}$ Antonella Tufano, MD, $\mathrm{PhD}^{2}$ Maria Esposito, MD ${ }^{1}$ \\ Francesco D'Agostino, MD ${ }^{1}$ Aniello Casoria, MD ${ }^{2}$ Filomena Capasso, BSc ${ }^{3}$ \\ Giovanni Di Minno, MD²
}

\author{
${ }^{1}$ Department of Hematology and Bone Marrow Transplantation, \\ University of Naples "Federico II," Naples, Italy \\ ${ }^{2}$ Department of Clinical Medicine and Surgery, University of Naples \\ "Federico II," Naples, Italy \\ ${ }^{3}$ Department of Molecular Medicine and Medical Biotechnology, \\ University of Naples “Federico II," Naples, Italy
}

Semin Thromb Hemost 2022;48:124-126.

Inhibitors directed against factor V (FV) occur seldom, primarily in the elderly, and the clinical presentation varies from asymptomatic laboratory abnormalities to life-threatening bleedings. ${ }^{1,2}$ Acquired FV inhibitors usually are immunoglobulin of the $G$ class ( $\operatorname{IgG}$ ) directed to the binding site for phosphatidylserine (present in the second C-type domain of the light chain of FV). Infections, drugs, surgical procedures, blood transfusions, solid and hematological cancers, and autoimmune disorders are associated with the risk of developing acquired FV inhibitors. ${ }^{3,4}$ According to the specific targeted epitope (i.e., domains of light chain or heavy chain of $\mathrm{FV}$ ), anti-FV antibodies affect the balance between pro- and anticoagulant functions of $\mathrm{FV}^{2,5}$ No definitive treatment strategy has been established. In approximately $50 \%$ of cases, the inhibitor is eliminated spontaneously. ${ }^{1-3}$

A 62-year-old Caucasian woman presented to the Hematology Department because of recurrent episodes of hematuria from 1 week, and bleeding from the sites of venous sampling. Coagulation tests showed that the platelet count was normal ( - Table 1): prolonged prothrombin time (PT): 45.5 seconds, international normalized ratio: 4.09 , and activated partial thromboplastin time (aPTT): 165 seconds, aPTT ratio: 5.5. Coagulation factor II (FII), factor X (FX), factor VIII (FVIII), and fibrinogen were normal. The FV activity was $0.1 \%$ (range of normality $60-120 \%$ ). The PT, aPTT, and one-stage coagulation factors assays were performed using an ACL TOP 550 coagulometer, and factor $\mathrm{V}$ was determined using a onestage PT-based assay (using Recombiplastin 2G, Instrumental Laboratory Spa), and factor V-deficient substrate plasma (Hemosil, Instrumental Laboratory Spa). Anti-cardiolipin antibodies were negative. Mixing test of patient's plasma with normal pooled plasma revealed the existence of an FV inhibitor, with an activity level of 4.0 Bethesda unit $/ \mathrm{mL}$ (Nijmegen modification of the Bethesda method)

published online September 24, 2021
Issue Theme Maintaining Hemostasis and Preventing Thrombosis in COVID-19-Part III; Guest Editors: Emmanuel J. Favaloro, PhD, FFSc (RCPA) and Giuseppi Lippi, MD

Address for correspondence Antonella Tufano, MD, PhD, Department of Clinical Medicine and Surgery, "Federico II" University Hospital, Via S. Pansini 5, 80131 Naples, Italy (e-mail: atufano@unina.it).

(-Table 1). Two weeks before, the patient had been treated for coronavirus disease 2019 (COVID-19) at home, with steroids (dexamethasone $6 \mathrm{mg}$ daily for 5 days), enoxaparin 4,000 IU daily, and oxygen. The clinical history of the patient included type 2 diabetes mellitus and arterial hypertension. At the time of diagnosis of FV inhibitor, antibodies against severe acute respiratory syndrome coronavirus 2 (SARSCoV-2) IgG were positive: $140 \mathrm{AU} / \mathrm{mL}$ (positive $>25$ ). Antinuclear antibodies were negative and C-reactive protein was $<0.33$ (range of normality: $0-0.5$ ). To eradicate the inhibitor, the patient was treated with dexamethasone $7.5 \mathrm{mg}$ daily. Hematuria stopped soon after beginning treatment with dexamethasone, and the abnormalities in PT and aPTT improved and normalized in about 2 weeks ( - Table 1 ). Presently the patient is clinically well and is monitored on an outpatient basis with periodic coagulation tests.

Previous reports have shown that acquired FV inhibitors are associated with transient mild bleeding episodes, and they frequently disappear in less than a month. ${ }^{1}$ This resembles the findings of our patient which is the second reported case of acquired FV inhibitor following COVID-19. ${ }^{6}$ Severe anemia, left psoas muscle hematoma, and left retroperitoneal cavity hematoma with FV activity $<1 \%$ and FV inhibitor titer of 31.6 Bethesda unit $/ \mathrm{mL}$ were reported in the first case in a patient with SARS-CoV-2 RNA testing positivity of the nasopharynx 2 weeks before presentation and for the following 4 weeks. ${ }^{6}$ The patient reported by Bennett et al did not respond to intravenous immunoglobulin and dexamethasone. Three cycles of plasma-exchange with fresh frozen plasma replacement resulted in the correction of bleeding and laboratory coagulopathy in that report. ${ }^{6}$

The incidence of acquired FV inhibitors is extremely low, with a rate of 0.023 to 0.09 per million persons per year. ${ }^{3}$ The

(c) 2021. Thieme. All rights reserved. Thieme Medical Publishers, Inc., 333 Seventh Avenue, 18th Floor, New York, NY 10001, USA
DOI https://doi.org/ 10.1055/s-0041-1735452. ISSN 0094-6176. 
Table 1 Evolution of coagulation tests from the start of steroid therapy

\begin{tabular}{|l|l|l|}
\hline Test & Values at day 1 (range of normality) & After 2 wk steroids \\
\hline INR & 4.09 & 1.04 \\
\hline Mixing test (INR) & 1.79 & \\
\hline APTT (ratio) & $5.50(0.8-1.2)$ & 0.71 \\
\hline Mixing test (APTT) & 1.92 & \\
\hline Fibrinogen (mg/dL) & $412(160-350)$ & 160 \\
\hline FV (\%) & $0.1 \%(60-120)$ & $65.5 \%$ \\
\hline FV mix & $9.7 \%$ & \\
\hline FVIII (\%) & $101 \%(50-130)$ & $248 \%$ \\
\hline FII $(\%)$ & $46 \%(60-120)$ & $88 \%$ \\
\hline FX $(\%)$ & $91 \%(60-120)$ & $205 \%$ \\
\hline FV inhibitor $(\mathrm{BU} / \mathrm{mL})$ & $4.0 \mathrm{BU} / \mathrm{mL}(<0.5)$ & $0.0 \mathrm{BU} / \mathrm{mL}$ \\
\hline
\end{tabular}

Abbreviations: APTT, activated partial thromboplastin time; BU, Bethesda Units; FV, factor V; INR, international normalized ratio.

presence of both prolonged PT and aPTT (not corrected after mixing with normal plasma), and an isolated FV deficiency, in a patient with a negative personal/familial bleeding history, leads to the initial diagnosis of acquired FV inhibitor. The inhibitor is confirmed and titrated using the Bethesda method. $^{7-9}$ Some patients with acquired FV inhibitors present with abnormal clinical laboratory tests but have no hemorrhagic symptoms. Others experience life-threatening bleedings. Mucosal (i.e., gastrointestinal, genitourinary, airways) bleedings account for more than $60 \%$ of the clinical manifestations. Hematuria, often severe, complicated the clinical phenotype in approximately half of the cases. ${ }^{1}$ Thrombosis can also occur, when the inhibitors interfere with the cofactor activity of FV for activated protein $C$. In rare cases a lupus-anticoagulant-like activity was also demonstrated. ${ }^{3,8}$

Data regarding the management of acquired FV inhibitor are mostly based on case reports. Treatment includes hemostatic and immunosuppressive therapy. Corticosteroids or IVIG, and transfusion support in patients with severe bleeding are the most used treatments. ${ }^{1,2}$ Some reports have shown that the administration of rituximab, cyclophosphamide, and plasma-exchange can be used. ${ }^{1,2}$ However, no definitive treatment strategy has been established, and, in approximately $50 \%$ of cases, the inhibitor is eliminated spontaneously. ${ }^{3}$

Coagulation abnormalities, thrombosis, and endothelial dysfunction are commonplace in patients with COVID-19, with higher incidence in severe cases, and the severity of alterations of coagulation parameters has been clearly associated with unfavorable prognosis. Thromboses are frequent in patients with severe COVID-19, while bleeding tendency in these patients is uncommon, and described as possible consequence of imbalances in platelet production/disruption, coagulation disorders, and antithrombotic prophylaxis. ${ }^{10-14}$ This second case of acquired FV deficiency should be added to the already reported cases of acquired factor VIII deficiency (acquired hemophilia A) ${ }^{15,16}$ in this infection and argue for an improvement in coagulation monitoring in patients with COVID-19 and otherwise unexplained hemorrhagic picture and/or abnormal prolongation of coagulation tests (PT and/or aPTT). However, we would like to emphasize that a causal relationship in our and other published cases is unproven, and that coincident findings of acquired inhibitors and COVID-19 are possible, as indeed are coincident findings of acquired inhibitors and COVID-19 vaccination. ${ }^{17}$

\section{Authors' Contributions}

F.C. and A.T. were responsible for conceiving the idea. A.T. wrote the manuscript and did the literature search. G.D.M. was responsible for critical revision of the manuscript. All the authors contributed to the approval of final manuscript.

Conflict of Interest

None declared.

\section{References}

1 Franchini M, Lippi G. Acquired factor V inhibitors: a systematic review. J Thromb Thrombolysis 2011;31(04):449-457

2 Goulenok T, Vasco C, Faille D, et al; RAVI study group. Acquired factor V inhibitor: a nation-wide study of 38 patients. $\mathrm{Br} \mathrm{J}$ Haematol 2021;192(05):892-899

3 Yamada S, Asakura H. Acquired factor V inhibitor. Rinsho Ketsueki 2020;61(07):791-798

4 Emori Y, Sakugawa M, Niiya K, et al. Life-threatening bleeding and acquired factor $\mathrm{V}$ deficiency associated with primary systemic amyloidosis. Blood Coagul Fibrinolysis 2002;13(06): 555-559

5 Matsumoto T, Nogami K, Shima M. Coagulation function and mechanisms in various clinical phenotypes of patients with acquired factor V inhibitors. J Thromb Haemost 2014;12(09): 1503-1512

6 Bennett J, Cunningham MT, Howard C, Hoffmann M, Plapp FV. Acquired factor $\mathrm{V}$ inhibitor in the setting of coronavirus disease 2019 infection. Blood Coagul Fibrinolysis 2021;32 (04):294-297

7 Franchini M, Targher G, Montagnana M, Lippi G. Laboratory, clinical and therapeutic aspects of acquired hemophilia A. Clin Chim Acta 2008;395(1-2):14-18

8 Ortel TL. Clinical and laboratory manifestations of anti-factor V antibodies. J Lab Clin Med 1999;133(04):326-334 
9 Favaloro EJ, Bonar R, Duncan E, et al; RCPA QAP in Haematology Haemostasis Committee. Identification of factor inhibitors by diagnostic haemostasis laboratories: a large multi-centre evaluation. Thromb Haemost 2006;96(01):73-78

10 Iba T, Levy JH, Levi M, Thachil J. Coagulopathy in COVID-19. J Thromb Haemost 2020;18(09):2103-2109

11 Hadid T, Kafri Z, Al-Katib A. Coagulation and anticoagulation in COVID-19. Blood Rev 2021;47:100761

12 Levi M, Thachil J, Iba T, Levy JH. Coagulation abnormalities and thrombosis in patients with COVID-19. Lancet Haematol 2020;7 (06):e438-e440

13 Marietta M, Coluccio V, Luppi M. COVID-19, coagulopathy and venous thromboembolism: more questions than answers. Intern Emerg Med 2020;15(08):1375-1387
14 Lippi G, Sanchis-Gomar F, Favaloro EJ, Lavie CJ, Henry BM. Coronavirus disease 2019-associated coagulopathy. Mayo Clin Proc 2021;96(01):203-217

15 Olsen GM, Rinder HM, Tormey CA. De novo acquired hemophilia as an immune dysregulation phenomenon following SARS-CoV-2 infection. Transfusion 2021;61(03):989-991

16 Franchini M, Glingani C, De Donno G, et al. The first case of acquired hemophilia A associated with SARS-CoV-2 infection. Am J Hematol 2020;95(08):E197-E198

17 Cittone MG, Battegay R, Condoluci A, et al. The statistical risk of diagnosing coincidental acquired hemophilia A following anti-SARS-CoV-2 vaccination. J Thromb Haemost 2021;19(09): 2360-2362 